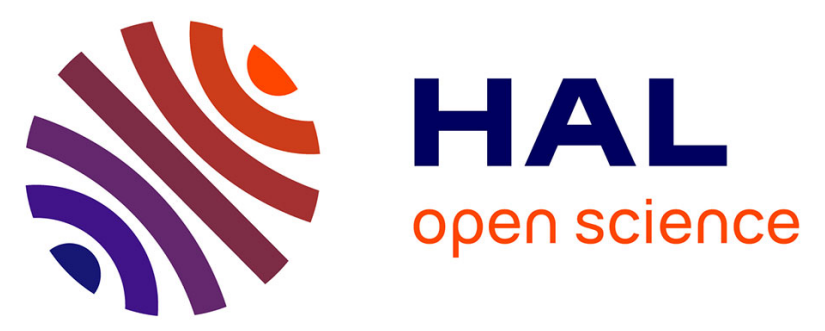

\title{
New n-type molecular semiconductor-doped insulator (MSDI) heterojunctions combining a triphenodioxazine (TPDO) and the lutetium bisphthalocyanine (LuPc2) for ammonia sensing
}

Amélie Wannebroucq, Guillaume Gruntz, Jean-Moïse Suisse, Yohann Nicolas, Rita Meunier-Prest, Mickaël Mateos, Thierry Toupance, Marcel Bouvet

\section{To cite this version:}

Amélie Wannebroucq, Guillaume Gruntz, Jean-Moïse Suisse, Yohann Nicolas, Rita Meunier-Prest, et al.. New n-type molecular semiconductor-doped insulator (MSDI) heterojunctions combining a triphenodioxazine (TPDO) and the lutetium bisphthalocyanine (LuPc2) for ammonia sensing. Sensors and Actuators B: Chemical, 2018, 255 (Part 2), pp.1694-1700. 10.1016/j.snb.2017.08.184 . hal02295973

\section{HAL Id: hal-02295973 \\ https://hal.science/hal-02295973}

Submitted on 24 Sep 2019

HAL is a multi-disciplinary open access archive for the deposit and dissemination of scientific research documents, whether they are published or not. The documents may come from teaching and research institutions in France or abroad, or from public or private research centers.
L'archive ouverte pluridisciplinaire HAL, est destinée au dépôt et à la diffusion de documents scientifiques de niveau recherche, publiés ou non, émanant des établissements d'enseignement et de recherche français ou étrangers, des laboratoires publics ou privés. 


\section{Graphical Abstract}

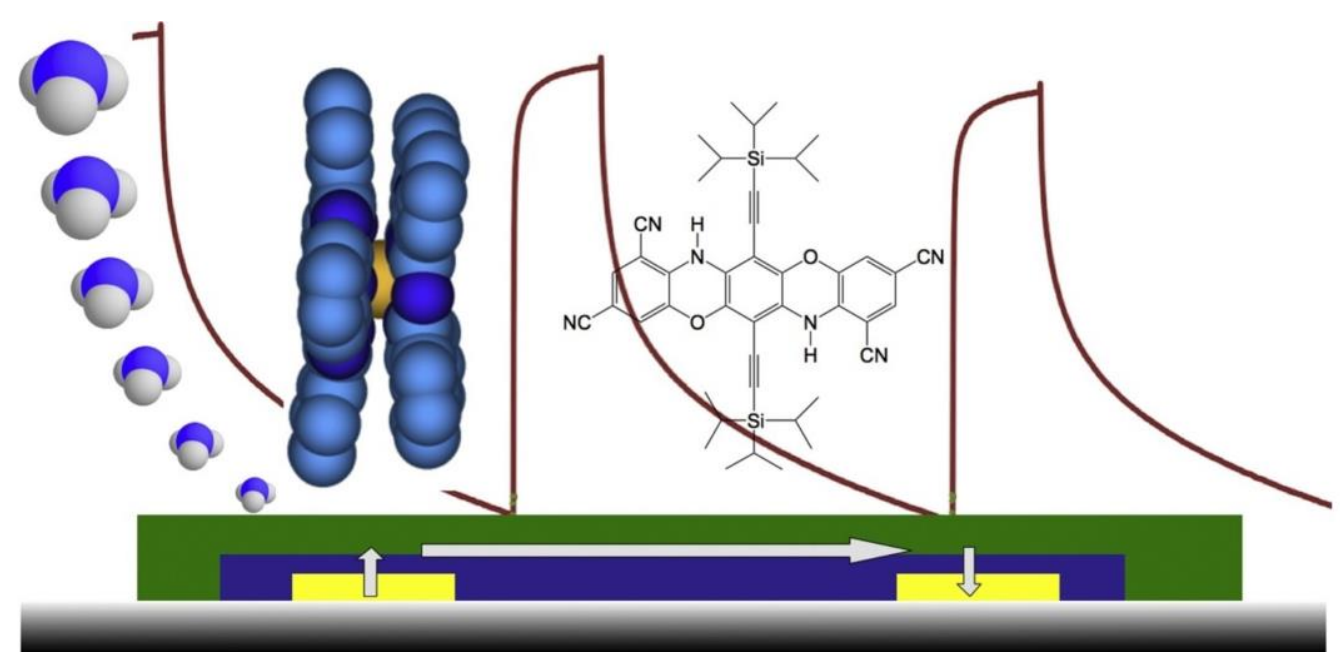

Highlights

- Reduced TPDO as a new active material in conductometric transducer.

- Evaporated TPDO leads to a stable n-type sensing behavior.

- Molecular material-based ammonia sensors operate at room temperature 


\title{
New n-type Molecular Semiconductor - Doped Insulator (MSDI) heterojunctions combining a triphenodioxazine (TPDO) and the lutetium bisphthalocyanine ( $\left.\mathrm{LuPc}_{2}\right)$ for ammonia sensing
}

Amélie Wannebroucq ${ }^{a}$, Guillaume Gruntz ${ }^{b}$, Jean-Moïse Suisse ${ }^{a}$, Yohann Nicolas ${ }^{b *}$, Rita Meunier-Prest ${ }^{a}$, Mickaël Mateos $^{a}$, Thierry Toupance ${ }^{b}$, Marcel Bouvet $^{a^{*}}$

anstitut de Chimie Moléculaire de l'Université de Bourgogne (ICMUB), UMR CNRS 6302, Univ. Bourgogne Franche-Comté, 9 avenue Alain Savary, 21078 Dijon cedex, France. Fax:+33-380-396-098; Tel: +33-380-396-086; E-mail: marcel.bouvet@u-bourgogne.fr bInstitut des Sciences Moléculaires (ISM), UMR 5255 CNRS, University of Bordeaux, 351 Cours de la Libération, 33405 Talence Cedex, France. Fax +33-540-006-994; Tel: +33-540002-523; E-mail: yohann.nicolas@enscbp.fr

\begin{abstract}
Molecular Semiconductor - Doped Insulator (MSDI) heterojunctions were designed using a new family of sublayers, namely triphenodioxazines (TPDO). The device obtained by combining the tetracyano triphenodioxazine bearing two triisopropylsilylethynyl moieties as a sublayer with the lutetium bisphthalocyanine $\left(\mathrm{LuPC}_{2}\right)$ as a top layer showed a nonlinear current-voltage characteristic independent of the sign of the polarization, which is the signature of MSDI heterojunctions. Thus, a TPDO was used in a chemical sensor for the first time. Despite $\mathrm{LuPC}_{2}$ being the only material exposed to the atmosphere, the positive response of the device under ammonia revealed the key role played by the $n$-type TPDO sublayer. The device exhibits a response stable over time and can operate in a broad range of relative humidity.
\end{abstract}

Keywords: Triphenodioxazine; Molecular materials; Heterojunctions; Conductometric transducer; Ammonia

\section{Introduction}

The wide attention that has been given to organic electronic devices over the past decades was due to their expected straightforward and low-cost processing through printing 
technologies as well as the possibility of designing flexible systems. In addition, new logic circuits and organic solar cells involve a suitable combination of $p$-type and n-type organic semiconductors. For example, a blend of poly-3-hexylthiophene and PCBM (a C60 derivative) used as p-type and n-type materials respectively is well known for its photovoltaic properties [1]. However, the number of $n$-type organic materials is so far rather limited compared to hole ( $p$-type) transporting materials. Thus, many efforts are currently devoted to the development of stable n-type organic semiconductors and to their integrations into n-type organic fieldeffect transistors and logic circuits [2-5].

A few years ago, Bouvet et al. introduced a new type of heterojunction [6], which is built from a rather poor conducting molecular material as sublayer covered by a highly conductive molecular material, the lutetium bisphthalocyanine (LuPc2, Scheme 1). Since the resistive sublayer is much thinner than the interelectrode distance, under polarization, charges have to move across the interface between the two molecular materials in order to take the most conductive pathway when applying a bias voltage, as shown in Fig. 1. This device has been named MSDI, which stands for Molecular Semiconductor - Doped Insulator heterojunction [7]. It is worth underlying that a MSDI is neither a p-n junction nor a transistor, and has its own current-voltage characteristics. Owing to its particularly low energy gap, ca. $0.5 \mathrm{eV}[8,9]$, resulting from its radical nature, the lutetium bisphthalocyanine exhibits a high density of positive and negative charge carriers, and, therefore, shows ambipolar conducting properties. Thus, $\mathrm{LuPC}_{2}$ is the first molecular semiconductor to have led to a $\mathrm{n}$-channel in an OFET [10].
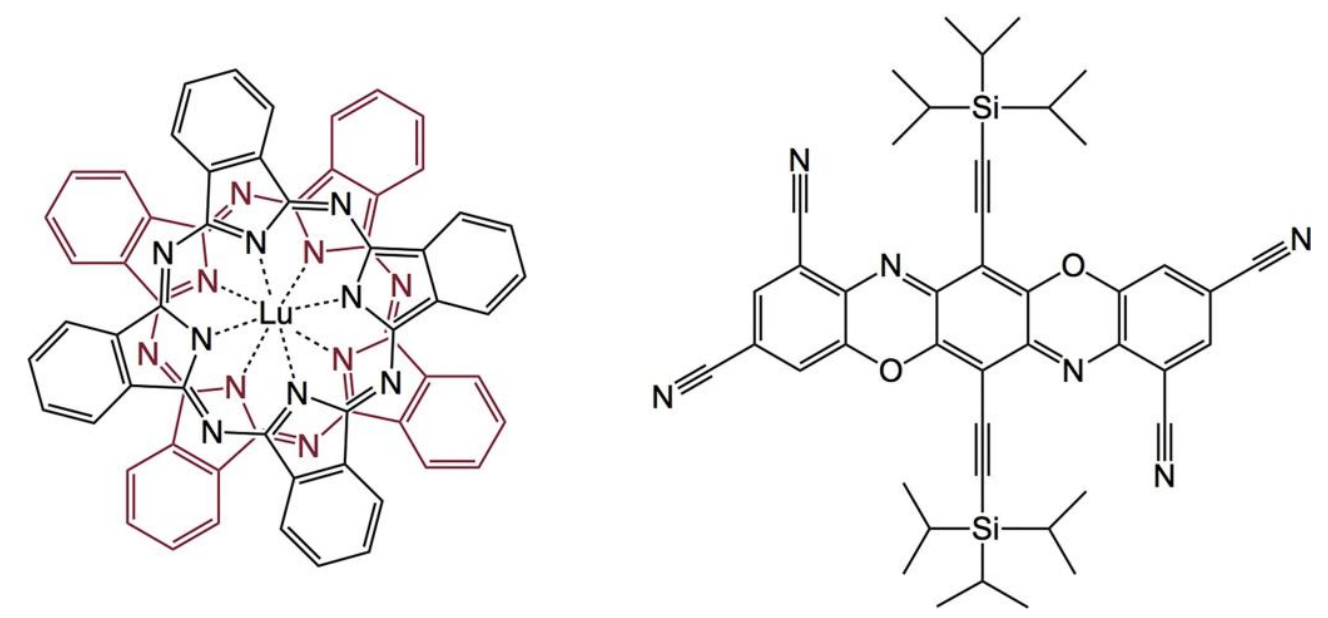

Scheme 1. Top view of $\mathrm{LuPc}_{2}$ along its $\mathrm{C}_{4}$ axis (left) and schematic view of the tetracyano-TIPSTPDO (right). 
This architecture involving $\mathrm{LuPc}_{2}$ exhibits very specific response when exposed to gases. Using pure n-type sublayers, such as metalloperfluorophthalocyanines, $\mathrm{M}\left(\mathrm{F}_{16} \mathrm{Pc}\right)$, the response to ammonia is positive whereas the electrical current decreases for a $\mathrm{LuPC}_{2}$ resistor. On the other hand, with a pure p-type sublayer, e.g. pentacene, oligothiophene or a nonsubstituted phthalocyanine $[7,11]$, ammonia induces a decrease in the current through the MSDI. An important point about MSDIs is that the only material that can interact with the outer atmosphere is the top layer. Nevertheless, we showed that the transport properties are dominated not only by the energy barrier at the interface between the sublayer and the LuPc ${ }_{2}$ top layer, but also by the Schottky contact between the sublayer and the electrodes [12]. These energy barriers are higher with $\mathrm{M}\left(\mathrm{F}_{16} \mathrm{Pc}\right)$ than with $\mathrm{p}$-type sublayers.

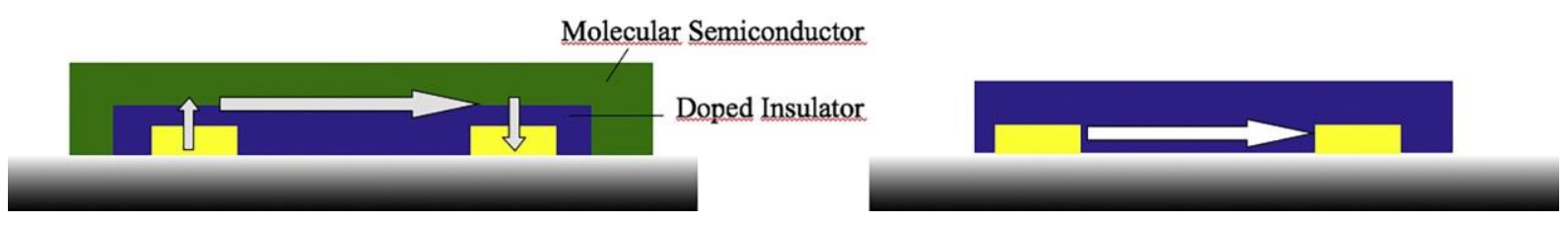

Figure 1. Schematic view of a Molecular Semiconductor - Doped Insulator (MSDI) heterojunction (left) compared to a resistor (right); the arrows indicate the main channel for charge carriers.

Beside perfluorinated phthalocyanines [13], only few molecular materials exhibit an n-type behavior in air. The most popular are naphthalene diimide and perylene diimide derivatives [4,14-16], C60 [17,18] and fluorinated oligothiophenes [5]. On the other hand, triphenodioxazine (TPDO) is a well-known $\pi$-conjugated core found in different dyes or pigments [19] that has recently found new promising development in the field of organic solar cells [20], dye-sensitized solar cells [21], luminescent devices [22] and organic field-effect transistors [23,24]. For instance, triphenodioxazines (TPDOs) bearing triisopropylsilylethynyl (TIPS) groups were introduced as new soluble n-type materials [21,24] (scheme 1). More interestingly, tetracyano-TIPS-TPDO proved to be an efficient material for liquid-processed air-stable n-type OFET $[25,26]$.

In the present paper, we report on the behavior of MSDI heterojunctions combining the tetracyano-TIPS-TPDO and the lutetium bisphthalocyanine LuPc 2 (Scheme 1). Their current- 
voltage characteristics are compared to those of resistors prepared from one of these two molecular materials. Their response to ammonia is studied in the $10-100 \mathrm{ppm}$ range, in synthetic air.

\section{Experimental}

\subsection{Chemicals}

Previously reported procedures were followed to prepare $\operatorname{LuPC}_{2}[27,28]$ and tetracyano-TIPSTPDO [25]. Chloroform and chlorobenzene are used as solvent for spin coating. Polystyrene $(\mathrm{M}=280000)$ and other chemicals are purchased from (Sigma-Aldrich) and used as received.

\subsection{Characterizations}

The UV-visible absorption spectra were registered using a Varian UV-vis spectrophotometer Cary 50, between $350 \mathrm{~nm}$ and $850 \mathrm{~nm}$. Field Desorption (FD) mass spectra were performed by the CESAMO (Bordeaux, France). The measurements were carried out on a TOF mass spectrometer AccuTOF GCv by JEOL using an FD emitter with an emitter voltage of $10 \mathrm{kV}$. One to two microliters solution of the compound was deposited on a $13 \mu \mathrm{m}$ emitter wire. Thermogravimetric analyses were carried out on a Netzsch STA simultaneous analyzer using alumina crucibles.

\subsection{Electrical and chemosensing measurements}

Electrical measurements were carried out with Indium Tin Oxide (ITO) interdigitated electrodes (IDE) deposited onto a $1 \times 1 \mathrm{~cm}^{2}$ glass substrate and separated by $75 \mu \mathrm{m}$. Their thickness was $50 \mathrm{~nm}$ and their total length $15 \mathrm{~cm}$. Thin films of molecular materials were prepared either by sublimation under secondary vacuum (ca. $10^{-6} \mathrm{mbar}$ ) in a UNIVEX 250 thermal evaporator (Oerlikon, Germany), at a rate of ca. $0.3 \AA \mathrm{s}^{-1}$, by heating in a temperature range of $320-350^{\circ} \mathrm{C}$ for TPDO and at a rate of $1 \AA \mathrm{s}^{-1}, 450-500$ ${ }^{\circ} \mathrm{C}$ for $\mathrm{LuPC}_{2}$, or by the spin coating technique. Thus, films of pure TPDO and films of TPDO mixed with $13 \%(\mathrm{w} / \mathrm{w})$ of polystyrene were prepared from chloroform/chlorobenzene $9 / 1$ solutions. The temperature of the solution was raised to $50^{\circ} \mathrm{C}$ before spin coating. The workbench used for the study of ammonia sensing was described previously [29]. Ammonia gas $\left(\mathrm{NH}_{3}\right), 1000 \mathrm{ppm}$ in synthetic air, and synthetic air were used from standard cylinders, purchased from Air Liquide, France. The total 
flow was in the 0.5-0.55 NL min ${ }^{-1}$ range, depending on ammonia concentration, and the volume of the test chamber was $8 \mathrm{~cm}^{3}$. Gas sensing experiments were carried out in a dynamic way, with 4 min-long rest periods alternating with 1 min-long exposure periods. In the present study, all the exposures to $\mathrm{NH}_{3}$ were carried out in dry air and at the lab temperature $\left(18-22^{\circ} \mathrm{C}\right.$, unless otherwise specified).

\section{Results and Discussion}

After deposition of TPDO by spin coating, LuPc2 $(50 \mathrm{~nm})$ was deposited by evaporation under secondary vacuum. The UV-visible spectrum of the resulting bilayer film exhibits the main absorption bands of TPDO, between 500 and $650 \mathrm{~nm}[24,25]$, with a peak at $638 \mathrm{~nm}$, and of $\mathrm{LuPc}_{2}$, with its $Q$ band at $668 \mathrm{~nm}$ and the weak band at $467 \mathrm{~nm}$ attributed to a transition between a filled orbital and the SOMO (Fig. 2) [30,31].

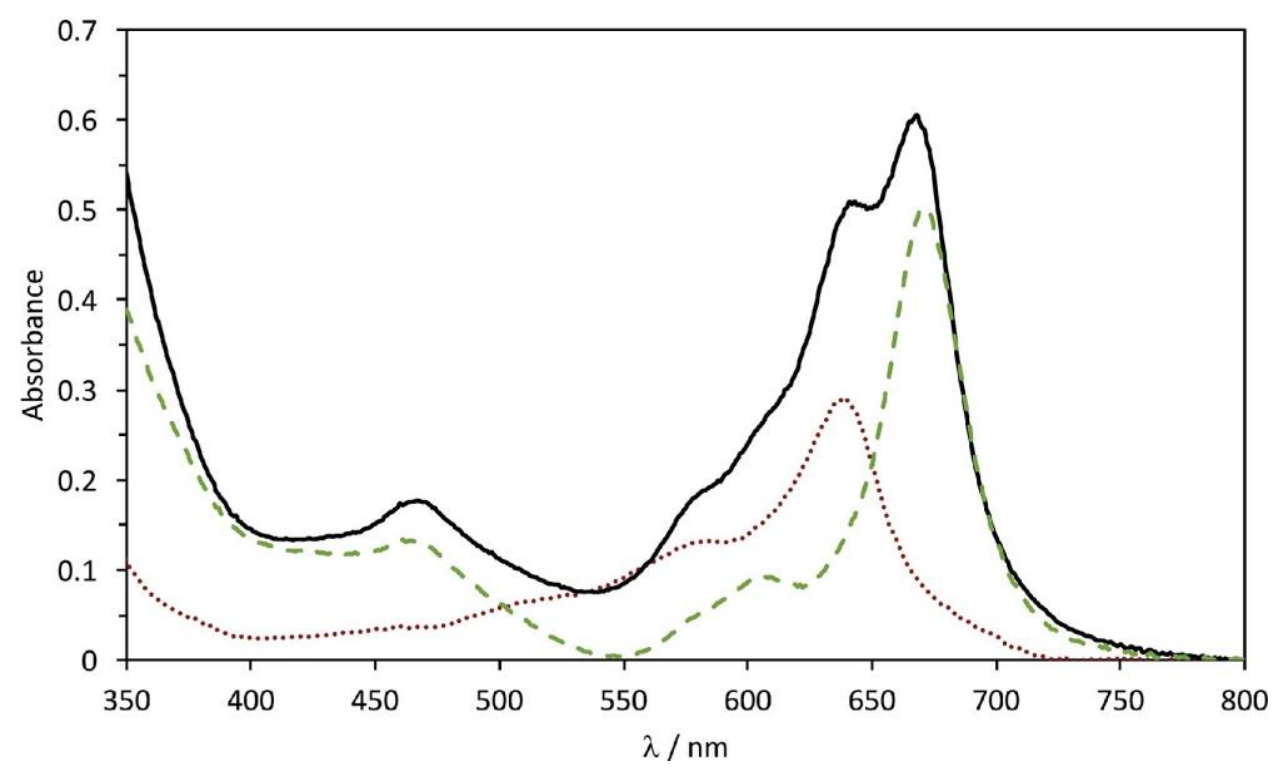

Figure 2. UV-vis absorption spectrum of a spin coated TPDO/LuPc 2 (black line) bilayer deposited on a glass substrate compared to the spectra of spin coated TPDO (red, dotted line) and evaporated $\mathrm{LuPc}_{2}$ (green, dashed line) films.

The I-V characteristics, registered from -10 to $+10 \mathrm{~V}$, are symmetrical and slightly nonlinear, with a current of $7 \times 10^{-5} \mathrm{~A}$ at $10 \mathrm{~V}$ (Fig. 3 left). Under a constant polarization of $1 \mathrm{~V}$, the device exhibits a current increase under $\mathrm{NH}_{3}$ (Fig. 3 right), as expected for a n-type MSDI. This clearly confirms the n-nature of the majority charge carriers in the TPDO sublayer. Indeed, MSDIs built with a p-type sublayer lead to a negative response to donating species like $\mathrm{NH}_{3}$ [7]. However, the response is rather poor. With 
exposure/recovery cycles of $1 \mathrm{~min} / 4 \mathrm{~min}$, the relative response to $90 \mathrm{ppm} \mathrm{NH}$ after a 1 min-long exposure period, defined as $\left(I-I_{0}\right) / I_{0}$, where $I$ and $I_{0}$ are the current values at the end and at the beginning of exposure periods, respectively, is only $0.2 \%$. More important is the evolution of the transport properties of the device. After a series of expositions to $\mathrm{NH}_{3} /$ rest under synthetic air cycles, the I- $\mathrm{V}$ characteristics become linear and $\mathrm{NH}_{3}$ induces a current decrease, indicating a modification of the electronic transport through the device, the origin of which remains unknown. This behavior was observed for samples prepared with pure TPDO and also for these from TPDO solutions containing $13 \%(\mathrm{w} / \mathrm{w})$ of polystyrene.
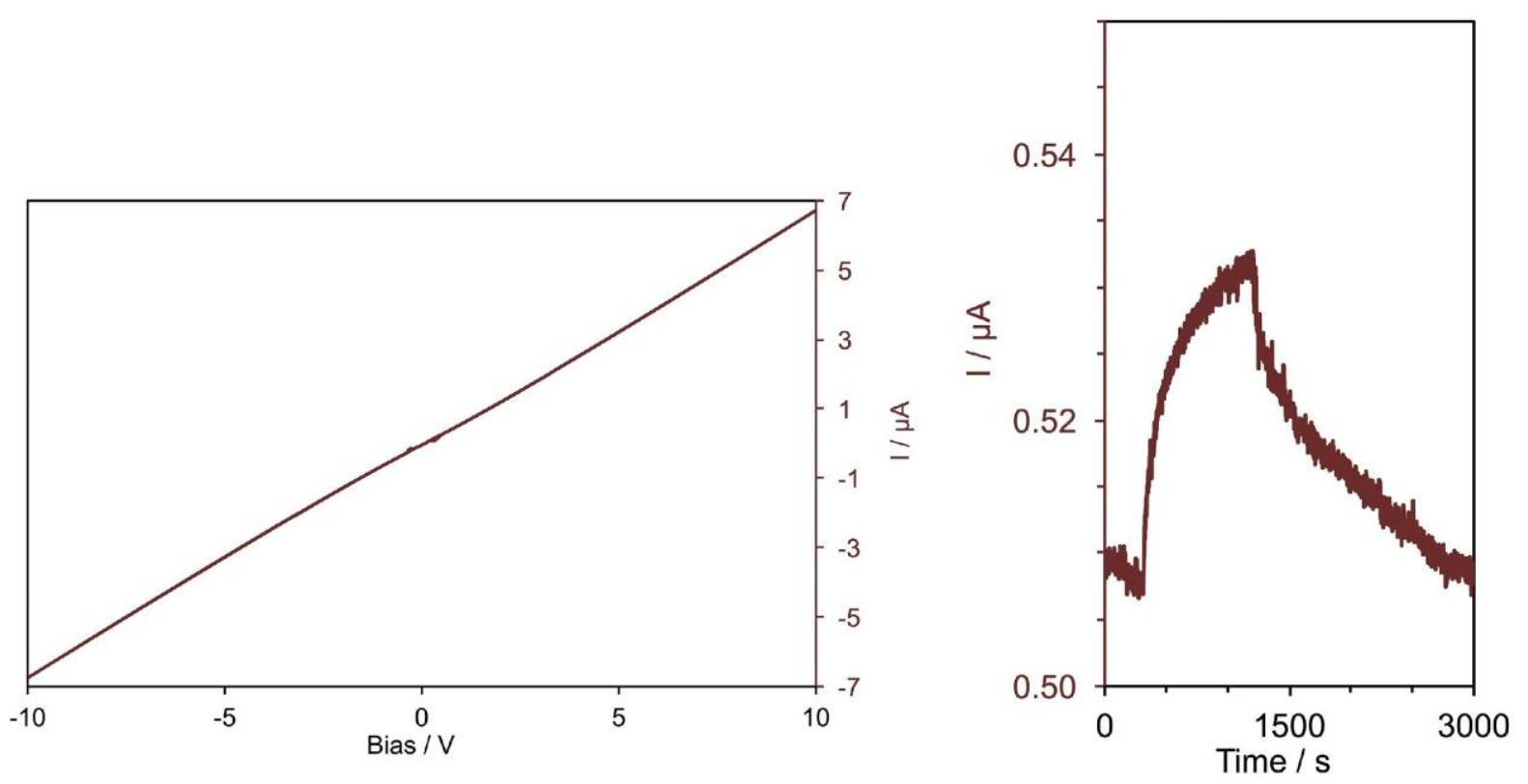

Figure 3. Typical I-V characteristic of a spin coated TPDO/LuPC2 MSDI (left) and its response to $90 \mathrm{ppm}$ of $\mathrm{NH}_{3}$ (exposure duration: $15 \mathrm{~min}$ ) in dry synthetic air when polarized at $1 \mathrm{~V}$ (right).

This is the reason why devices were prepared by vacuum evaporation of both components, TPDO and $\mathrm{LuPC}_{2}$, with thicknesses of $50 \mathrm{~nm}$ each. They showed a significantly different behavior. In particular, their electrical characteristics and their chemosensing responses remain stable over time. The I-V characteristics are symmetrical and nonlinear, with a current of $1.35 \times 10^{2} \mu \mathrm{A}$ at $10 \mathrm{~V}$ (Fig. 4). When exposed to $\mathrm{NH}_{3}$, the current increases sharply during the first minute, up to a plateau, and a full reversibility is observed under synthetic air, as depicted from $15 \mathrm{~min} / 1 \mathrm{~h}$ exposure/rest cycles (Fig. 5). Again, this positive response to $\mathrm{NH}_{3}$ is the signature of a n-type MSDI. 


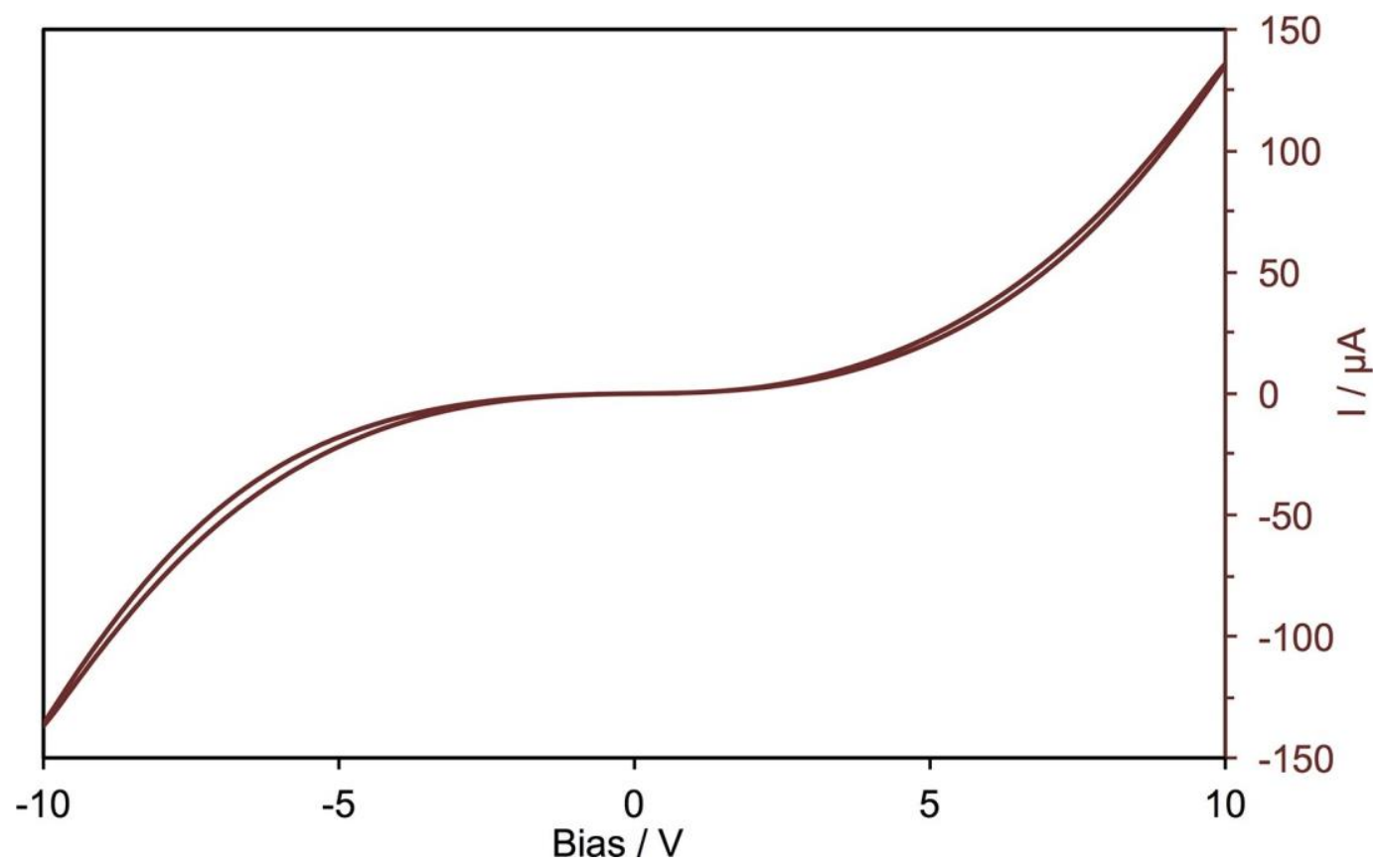

Figure 4. Typical I-V characteristic of a vacuum evaporated TPDO/LuPc2 MSDI.

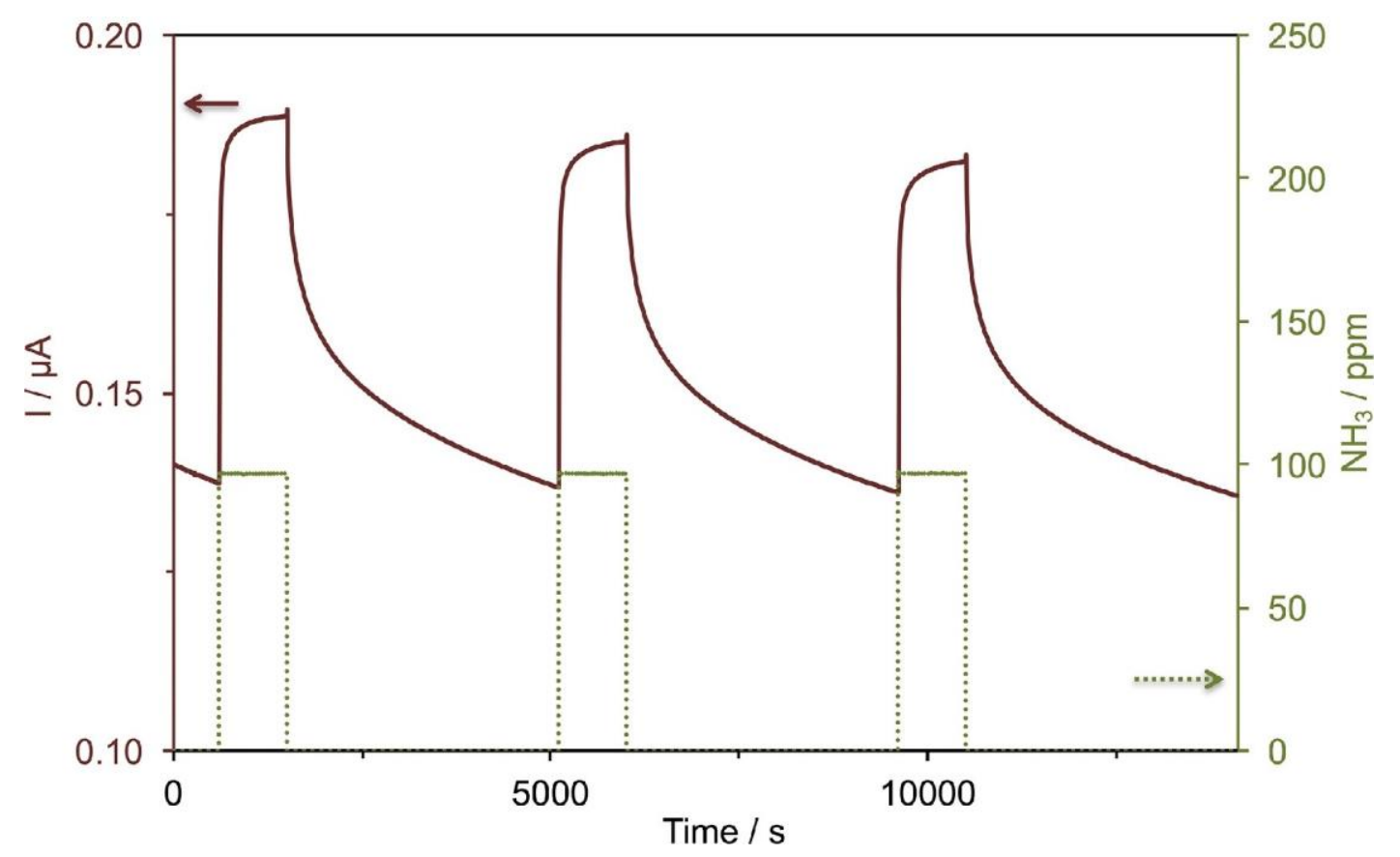

Figure 5. Current variation as a function of time of a vacuum deposited TPDO/LuPc 2 MSDI, polarized at $1 \mathrm{~V}$, exposed to $90 \mathrm{ppm} \mathrm{NH}_{3}$ for 15 min-long periods separated by $1 \mathrm{~h}$-long rest periods in dry synthetic air.

When submitted to repeated exposure/recovery cycles with exposure periods of 1 min separated by a 4 min-long recovery period under a synthetic air flow, the device shows a good reversibility, with only a slight drift. The response depends on the $\mathrm{NH}_{3}$ concentration, as depicted from Fig. 6 , in the $30-90$ ppm range. The relative response is about $11 \%$ at 30 ppm, 
which is as much as that of the most sensitive n-MSDI reported so far, namely the MSDIs prepared with perfluorophthalocyanine complexes as a sublayer.

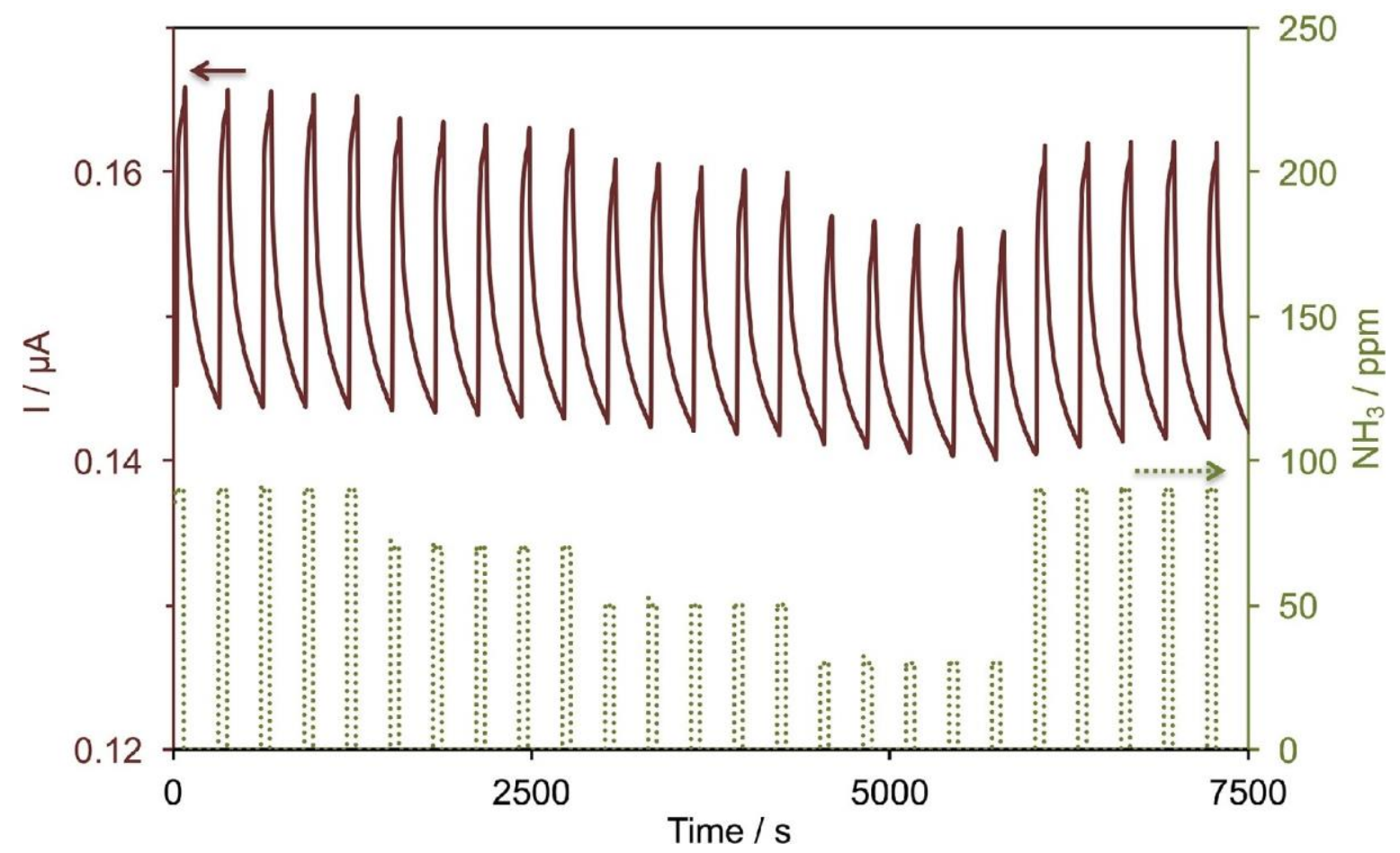

Figure 6. Response of a vacuum deposited TPDO/LuPc2 MSDI to $\mathrm{NH}_{3}$ in the range 30-90 $\mathrm{ppm})$, in dry atmosphere, during exposure/recovery cycles (1 $\mathrm{min} / 4 \mathrm{~min})$, polarized at $1 \mathrm{~V}$.

In comparison, a resistor made of a vacuum deposited TPDO film in the same conditions exhibits a much lower current, about $10^{-9} \mathrm{~A}$ under $10 \mathrm{~V}$. This increases under ammonia, by $6 \%$ after one minute at $50 \mathrm{ppm}$. However, the response changes only slightly between 25 ppm and 90 ppm (Fig. 7). Again, this curve shows the n-type character of the material. The important drift of the current with and without ammonia limits highly the interest of such a resistor. This drift was also observed when the resistor was exposed to $90 \mathrm{ppm}$ of $\mathrm{NH}_{3}$ during $15 \mathrm{~min} / 60 \mathrm{~min}$ exposure/recovery cycles (Fig. S1). The current drift is so high, with and without ammonia, that no plateau is visible. In turn, it highlights the advantages of the MSDI heterojunctions compared to resistors. 


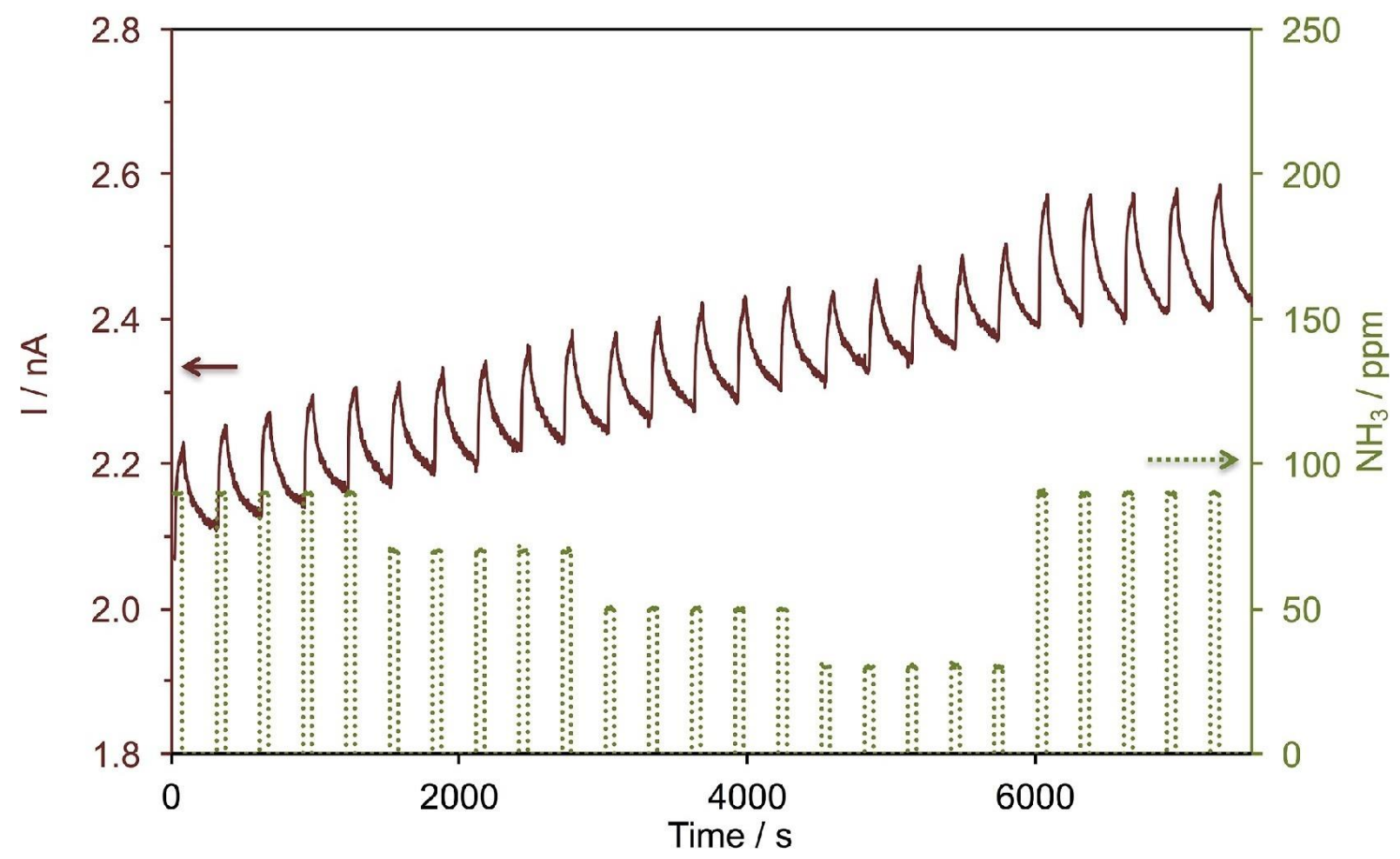

Figure 7. Current variation as a function of time of a vacuum deposited TPDO resistor, polarized at $10 \mathrm{~V}$, exposed to ammonia in dry synthetic air at different concentrations for 1 min-long periods spaced by a 4 min-long rest period under dry synthetic air. The ammonia concentration at each cycle is indicated on the right scale.

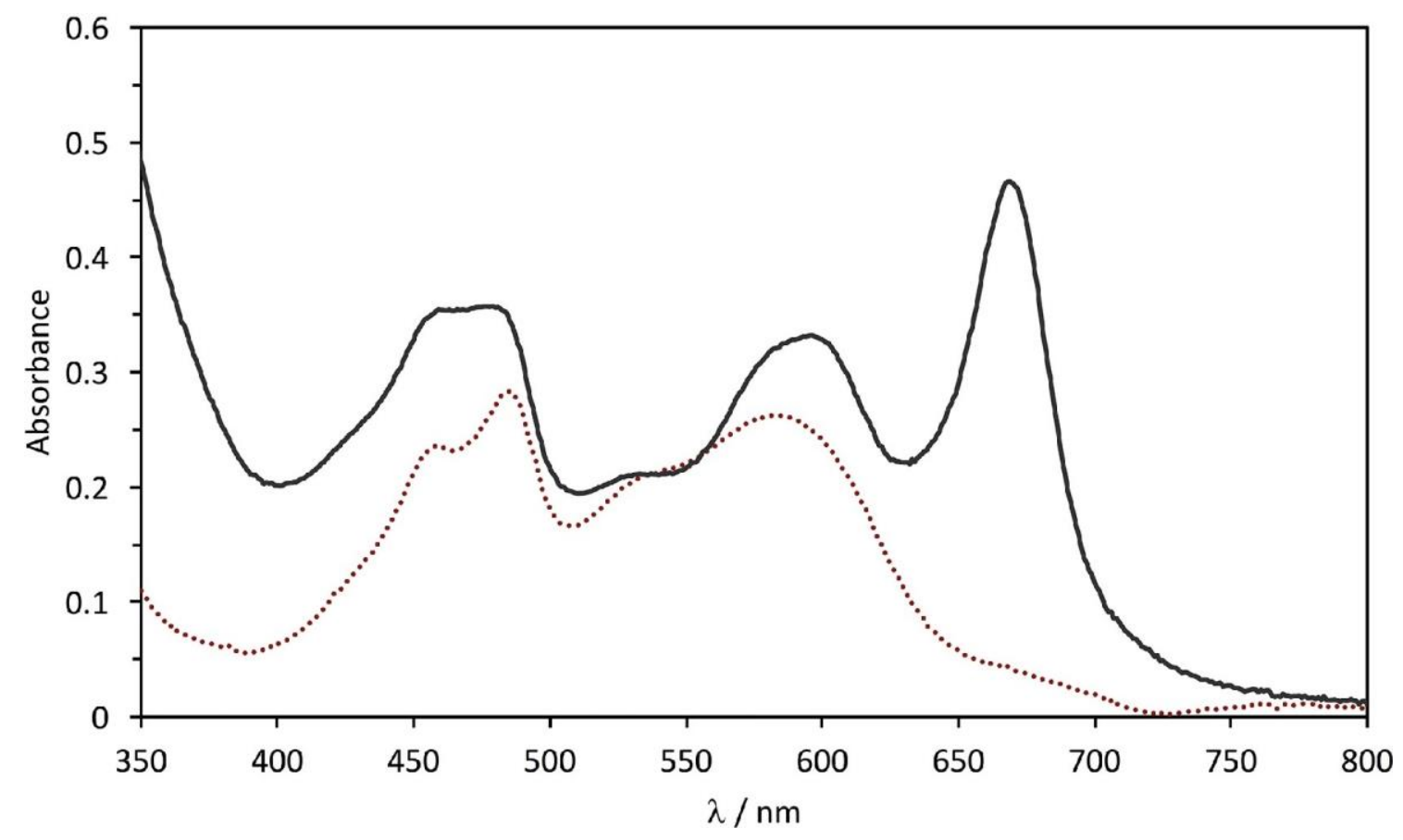

Figure 8. Absorption spectra of a vacuum evaporated TPDO/LuPc 2 MSDI ( $50 \mathrm{~nm} / 50 \mathrm{~nm}$ ) (top, black line) and of a vacuum evaporated TPDO resistor (50 nm, red dotted line) 
The UV-visible absorption spectra of vacuum evaporated TPDO films with and without LuPc2 as a top layer (Fig. 8) are different from those expected for TPDO and obtained by spin coating (Fig. 2) $[24,25]$. In particular, additional bands appear in the vacuum evaporated TPDO films, which are centered at 459,485 and $581 \mathrm{~nm}$, while the $\lambda_{\max }$ of spin coated TPDO films lies at $638 \mathrm{~nm}$. In the corresponding MSDIs, additionally to the $\mathrm{Q}$ band of $\operatorname{LuPc}_{2}(668 \mathrm{~nm})$, another feature is the absorption at $460 \mathrm{~nm}$, related to the radical nature of $\operatorname{LuPc}_{2}[30,31]$, that becomes equal to this at $479 \mathrm{~nm}$, owing to the absorption of both materials at this wavelength. The broad band centered at $596 \mathrm{~nm}$ results also from both materials, whereas the band at $638 \mathrm{~nm}$ (Fig. 2) corresponding to TPDO disappeared. These differences with the expected spectra are not due to a degradation of the TPDO molecule since it starts above 350 ${ }^{\circ} \mathrm{C}$ as depicted from thermogravimetric analyses. In addition, the mass spectrum of the evaporated derivative shows a main peak at an exact mass of 748.3365, which can be assigned to the diprotonated molecule, $\mathrm{H}_{2}$ TPDO (Fig. 9). The mass difference with the chemical formula, $\mathrm{C}_{44} \mathrm{H}_{48} \mathrm{~N}_{6} \mathrm{O}_{2} \mathrm{Si}_{2}$, is of $1.59 \mathrm{ppm}$, which is a very small value sign of an unambiguous assignment. For the native TPDO, the exact mass is $746.3193(\mathrm{M})$, and the first fragmentation corresponds to the loss of one of the propyl groups (M-43). This new formula $\left(\mathrm{H}_{2}\right.$ TPDO) corresponds to a reduction of the starting TPDO by two electrons and two protons, analogous to the reduction of quinones into dihydroquinones [32]. This reduction can occur at the quinonediimine level, by its transformation into its diamino analogue (Fig 9) [33]. Another characteristic of the reduced derivative is its thin vibration band at $3372 \mathrm{~cm}^{-1}$, attributed undoubtedly to a stretching vibration of a $\mathrm{N}-\mathrm{H}$ bond, which is absent in TPDO. The study of the reduction of TPDO in solution will be reported elsewhere [34]. While the native quinonediimine form of TPDO is stable in air, the reduced form, $\mathrm{H}_{2}$ TPDO, is produced during heating under secondary vacuum ( $\left.P=10^{-6} \mathrm{mbar}\right)$. The only way to explain the existence of this reduced form in the solid state is to take into account the intermolecular interactions, mainly $\pi-\pi$ interactions and $\mathrm{H}$ bonds, since the reduced form owns two additional $\mathrm{H}$ atoms, bear by nitrogen atoms, capable to form $\mathrm{H}$-bonds with neighboring molecules. 


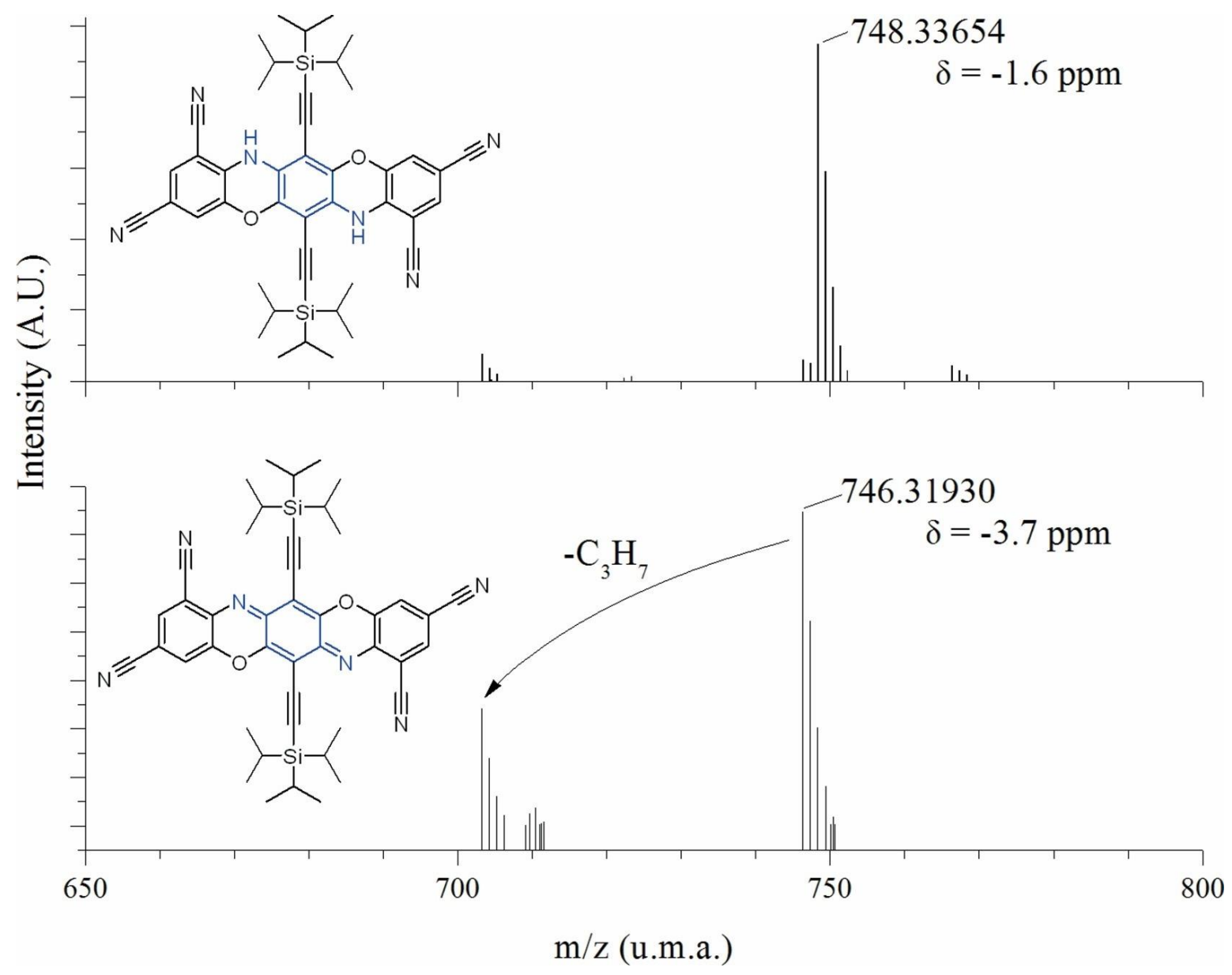

Figure 9. Mass spectra of the triphenodioxazine derivative (bottom) and its reduced form (top) obtained in positive mode. Chemical structures (only the two additional $\mathrm{H}$ atoms are shown in the reduced form), radical lost fragment, exact mass and differences with theoretical mass are inserted.

Resistors based on substituted bisphthalocyanine complexes with a good sensitivity to $\mathrm{NH}_{3}$ have been reported [35], with a positive or negative response, depending on the peripheral substitution of the macrocycles. However, clearly, as for the resistor made from TPDO derivatives in the present study, there is an important drift of the current over time. In an example [36] a response of ca. $2 \%$ at $10 \mathrm{ppm} \mathrm{NH}_{3}$ was reported but the current-time curve was noisy. We want to point out that the current response of MSDIs does not suffer this drawback. We previously underlined the advantage of $n$-type MSDIs for chemosensing (see for examples [6] and [11]). In particular, the high sensitivity of the radical LuPc2 top layer is kept, but with a higher stability of the response over time compared to resistors made from one of the components. Moreover, with a n-type sublayer, the response to $\mathrm{NH}_{3}$ is positive (current increase), which is always an advantage compared to a negative response. $\mathrm{n}$-Type 
semiconductors offer this advantage, but due to their poor long term stability in air, their use in resistors is de facto very limited. Their use in MSDI heterojunctions offers the opportunity to keep the advantage of $n$-type materials to detect electrodonating gases without their instability in air. A key difference between conventional resistors and n-MSDIs is that the responses to ammonia and humidity are inverted in n-MSDIs whereas these species act both as donating species in resistors. The effect of water was interpreted as an effect of trapping of positive charge carriers by water molecules leading to a decrease of the energy barrier in MSDIs, then an increase of the current going through the device. The effect of ammonia is the neutralization of positive charge carriers by ammonia leading to an increase in minority (negative) charge carriers, which govern the transport properties of $n$-type MSDIs [12].

The response of the vacuum evaporated TPDO/LuPc2 MSDI towards $\mathrm{NH}_{3}$ was study under humidity, in the range $10-70 \%$ (Fig. 10). The humidity decrease induces a slight drift of the current, by $4.5 \%$ from $70 \%$ rh to $10 \%$ rh. This variation is lower than the response to $30 \mathrm{ppm}$ $\mathrm{NH}_{3}$. The response to $\mathrm{NH}_{3}$ increases with the rh value, from $9.1 \%$ to $14.8 \%$ at $30 \mathrm{ppm} \mathrm{NH}$ when the rh increases from $10 \%$ to $70 \%$.

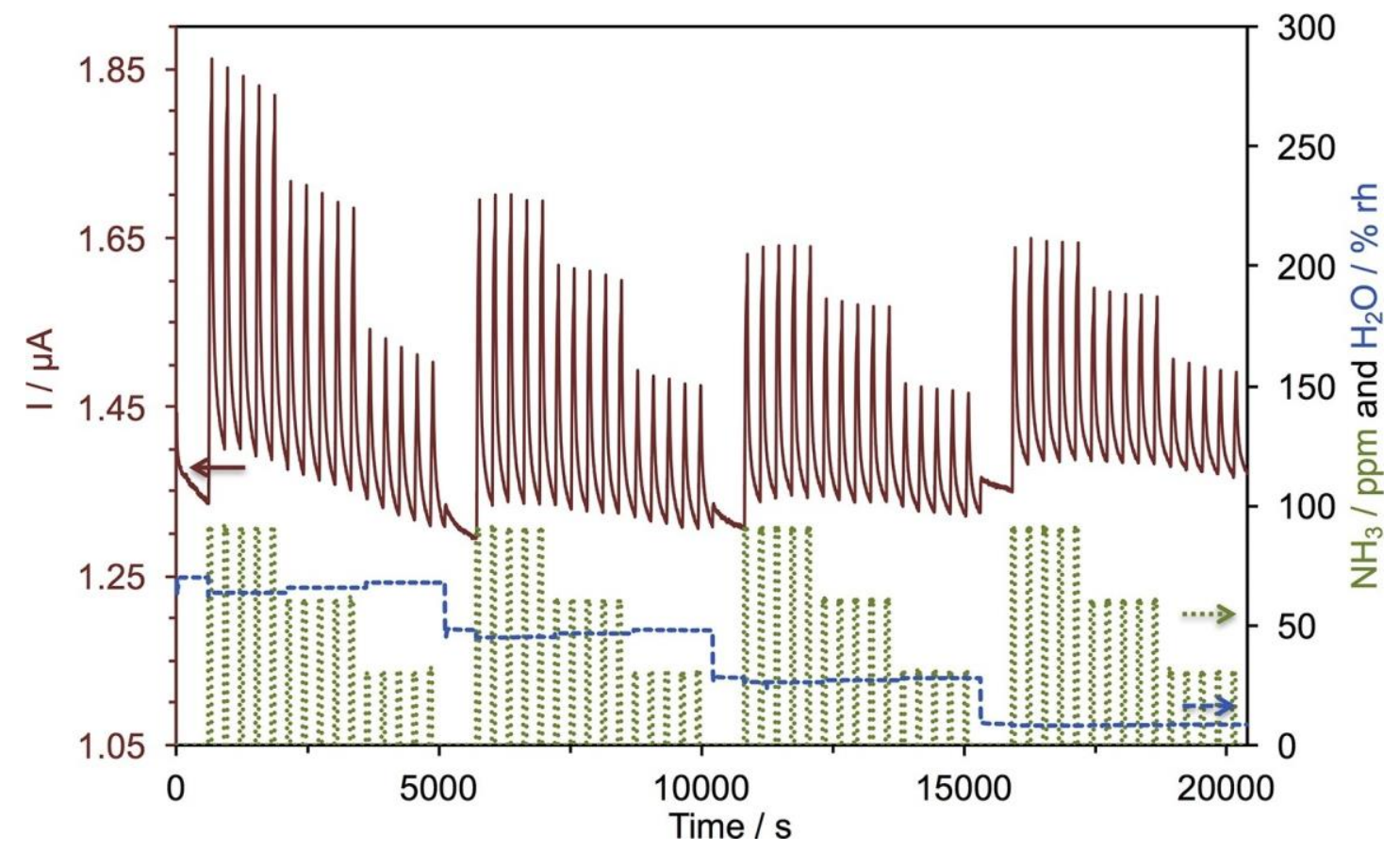

Figure 10. Response of a vacuum evaporated TPDO/LuPc 2 MSDI (solid line) to $\mathrm{NH}_{3}(90$, 60 and 30 ppm, dotted line), with relative humidity in the range 10-70 \% (dashed line), during exposure/recovery cycles $(1 \mathrm{~min} / 4 \mathrm{~min})$, polarized at $2 \mathrm{~V}$. The temperature was $23.5^{\circ} \mathrm{C}$. 
Up to now the reported n-type MSDI heterojunctions were limited to perylene derivatives and perfluorophthalocyanines. We already demonstrated a long-term stability of the chemosensing behavior of n-MSDIs with a perfluorophthalocyanine complex as a sublayer, namely several years [12]. On the contrary, perylene derivatives that exhibit rather nice responses to $\mathrm{NH}_{3}$ lead to sensors with a rather poor stability over time [29].

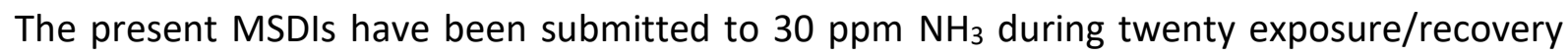
cycles (1 min/4 min) at $50 \%$ rh (Fig. 11). A small drift appears for the current with and without $\mathrm{NH}_{3}$ and the relative response remains constant over all the experiment, at $14.9 \% \pm 0.1$.

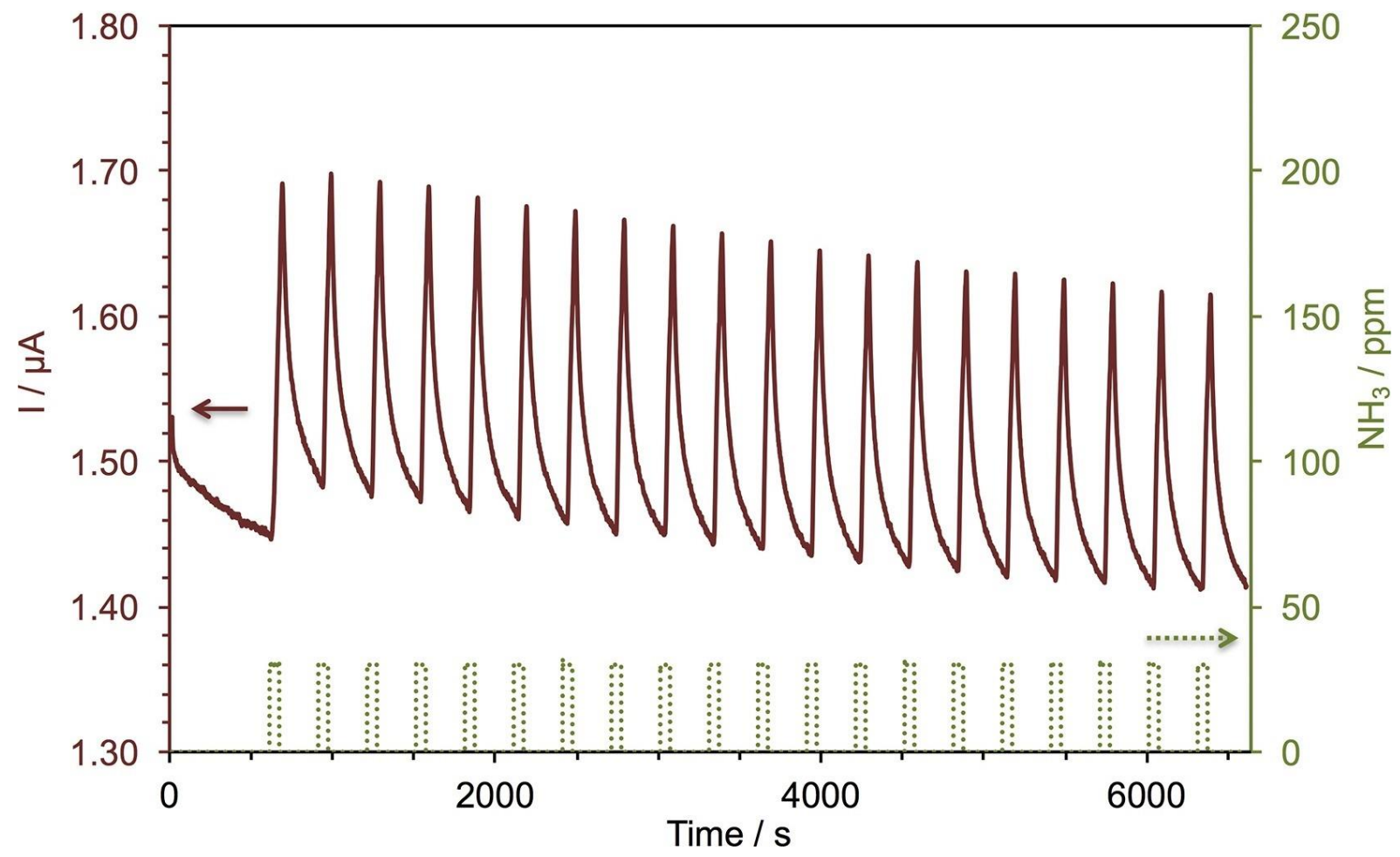

Figure 11. Response of a vacuum evaporated TPDO/LuPc $\mathrm{C}_{2} \mathrm{MSDI}$ (solid line) to $30 \mathrm{ppm}$ $\mathrm{NH}_{3}$ (dotted line) at a relative humidity of $50 \%$, during twenty exposure/recovery cycles $(1 \mathrm{~min} / 4 \mathrm{~min})$, polarized at $2 \mathrm{~V}$. The temperature was $23.5^{\circ} \mathrm{C}$.

So, with this present work we showed the interest of TPDO derivatives as a component in such conductometric sensors. It opens the way for new applications for this family of $n$-type materials already used in organic electronics, but in OFETs and in photovoltaic cells. 


\section{Conclusion}

Sensing ammonia with an MSDI involving $\mathrm{LuPc}_{2}$ and tetracyano-TPDO confirms the $\mathrm{n}$-type character of the conductivity of TPDO. The reduced form of the tetracyano-TPDO obtained during its vacuum evaporation revealed to be also a n-type material, with a better stability of its electrical and chemosensing properties when associated to $\mathrm{LuPc}_{2}$ in MSDI devices. The positive response to $\mathrm{NH}_{3}$ is high enough for its detection in the range 10-100 ppm, which is interesting for many applications. Thus, in chemical industry, the threshold of $50 \mathrm{ppm}$ is generally considered, and the European air quality labor legislation sets the daily exposure limit to $20 \mathrm{ppm}$ for $\mathrm{NH}_{3}$ [37]. It also confirms, if needed, that the MSDI device is a versatile conductometric transducer, capable of accommodating many molecular materials, and of operating at room temperature. TPDO derivatives favorably compete previous materials leading to n-type MSDIs, namely perfluorophthalocyanines and perylene derivatives.

\section{Acknowledgements}

The authors acknowledge the Agence Nationale de la Recherche for funding through the projects CAP-BTX ANR-BLAN-2010-917-02, FMOCSOLE ANR-BLAN-2010-938-01 and OUTSMART ANR-2015-CE39-0004-03 and the MENESR for a PhD grant (A. W.). Financial support from the European Union (FEDER) and the Conseil Régional de Bourgogne through the FABER and the PARI SMT 08 and CDEA programs is gratefully acknowledged. We would like to thank the European Union for funding through the COST action TD1105 EuNetAir. The University of Bordeaux (G.G. PhD support), the CNRS and the institute of polytechnique of Bordeaux are acknowledged for financial support.

\section{References}

[1] J. Peet, A.J. Heeger, G.C. Bazan, "Plastic" solar cells: Self-assembly of bulk heterojunction nanomaterials by spontaneous phase separation, Acc. Chem. Res. 42 (2009) 1700-1708. doi:10.1021/ar900065j.

[2] B. Crone, A. Dodabalapur, Y.Y. Lin, R.W. Filas, Z. Bao, A. LaDuca, et al., Large-scale complementary integrated circuits based on organic transistors, Nature. 403 (2000) 521-523. doi:10.1038/35000530.

[3] H. Klauk, M. Halik, U. Zschieschang, F. Eder, D. Rohde, G. Schmid, et al., Flexible organic complementary circuits, IEEE Trans. Electron Dev. 52 (2005) 618-622. doi:10.1109/TED.2005.844739.

[4] J. Zaumseil, H. Sirringhaus, Electron and ambipolar transport in organic field- 
[5] H. Usta, A. Facchetti, T.J. Marks, n-Channel semiconductor materials design for organic complementary circuits, Acc. Chem. Res. 44 (2011) 501-510. doi:10.1021/ar200006r.

[6] V. Parra, M. Bouvet, Semiconductor transducer and its use in a sensor for detecting electron-donor or electron-acceptor species, US8450725 B2.

[7] V. Parra, J. Brunet, A. Pauly, M. Bouvet, Molecular semiconductor-doped insulator (MSDI) heterojunctions: an alternative transducer for gas chemosensing, Analyst. 134 (2009) 1776-1778. doi:10.1039/b906786h.

[8] J.-J. André, K. Holczer, P. Petit, M.-T. Riou, C. Clarisse, R. Even, et al., Electrical and magnetic properties of thin films and single crystals of bis(phthalocyaninato)lutetium, Chem. Phys. Lett. 115 (1985) 463-466. doi:10.1016/0009-2614(85)85171-X.

[9] M. Bouvet, J. Simon, Electrical properties of rare earth bisphthalocyanine and bisnaphthalocyanine complexes, Chem. Phys. Lett. 172 (1990) 299-302. doi:10.1016/0009-2614(90)85407-4.

[10] G. Guillaud, M. Al Sadoun, M. Maitrot, J. Simon, M. Bouvet, Field-effect transistors based on intrinsic molecular semiconductors, Chem. Phys. Lett. 167 (1990) 503506.

[11] M. Bouvet, H. Xiong, V. Parra, Molecular semiconductor-doped insulator (MSDI) heterojunctions: Oligothiophene/bisphtalocyanine ( $\left.\mathrm{LuPc}_{2}\right)$ and perylene/bisphthalocyanine as new structures for gas sensing, Sens. Actuators: B. Chem. 145 (2010) 501-506. doi:10.1016/j.snb.2009.12.064.

[12] M. Bouvet, P. Gaudillat, A. Kumar, T. Sauerwald, M. Schüler, A. Schütze, et al., Revisiting the electronic properties of Molecular Semiconductor - Doped Insulator (MSDI) heterojunctions through impedance and chemosensing studies, Org. Electron. 26 (2015) 345-354. doi:10.1016/j.orgel.2015.07.052.

[13] Z. Bao, A.J. Lovinger, J. Brown, New air-stable n-channel organic thin film transistors, J. Am. Chem. Soc. 120 (1998) 207-208. doi:10.1021/ja9727629.

[14] H.E. Katz, A.J. Lovinger, J. Johnson, C. Kloc, T. Siegrist, W. Li, et al., A soluble and air-stable organic semiconductor with high electron mobility, Nature. 404 (2000) 478-481. doi:10.1038/35006603.

[15] H.E. Katz, J. Johnson, A.J. Lovinger, W. Li, Naphthalenetetracarboxylic diimidebased $\mathrm{n}$-channel transistor semiconductors: Structural variation and thiolenhanced gold contacts, J. Am. Chem. Soc. 122 (2000) 7787-7792. doi:10.1021/ja000870g.

[16] B.A. Jones, A. Facchetti, M.R. Wasielewski, T.J. Marks, Tuning orbital energetics in arylene diimide semiconductors. Materials design for ambient stability of n-type charge transport, J. Am. Chem. Soc. 129 (2007) 15259-15278. doi:10.1021/ja075242e.

[17] R.C. Haddon, A.S. Perel, R.C. Morris, T.T.M. Palstra, A.F. Hebard, R.M. Fleming, C60 thin film transistors, Appl. Phys. Lett. 67 (1995) 121-123. doi:10.1063/1.115503.

[18] H. Li, B.C.-K. Tee, J.J. Cha, Y. Cui, J.W. Chung, S.Y. Lee, et al., High-mobility fieldeffect transistors from large-area Ssolution-grown aligned C60 single crystals, J. Am. Chem. Soc. 134 (2012) 2760-2765. doi:10.1021/ja210430b.

[19] A.H.M. Renfrew, Reactive dyes for cellulose: Replacement of anthraquinone blues 
by triphenodioxazines, Color. Technol. 15 (1995) 15-20. doi:10.1111/j.14784408.1985.tb03731.x.

[20] L. Guo, J. Quinn, J. Wang, C. Guo, X. Li, J. Wang, et al., A fluorene-fused triphenodioxazine (FTPDO) based polymer with remarkable thermal stability and significantly enhanced charge transport performance in air, Dyes Pigments. 132 (2016) 329-335. doi:10.1016/j.dyepig.2016.05.011.

[21] Y. Nicolas, F. Allama, M. Lepeltier, J. Massin, F. Castet, L. Ducasse, et al., New synthetic routes towards soluble and dissymmetric triphenodioxazine dyes designed for dye-sensitized solar cells, Chem. Eur. J. 20 (2014) 3678-3688. doi:10.1002/chem.201303775.

[22] T. Tanaka, T. Ashida, S. Matsumoto, Highly dichroic and luminescent triphenodioxazine dyes, Chem. Lett. 40 (2011) 573-575. doi:10.1246/cl.2011.573.

[23] C.-A. Di, J. Li, G. Yu, Y. Xiao, Y. Guo, Y. Liu, et al., Trifluoromethyltriphenodioxazine: Air-stable and high-performance n-type semiconductor, Org. Lett. 10 (2008) 3025-3028. doi:10.1021/ol8008667.

[24] Y. Nicolas, F. Castet, M. Devynck, P. Tardy, L. Hirsch, C. Labrugère, et al., TIPStriphenodioxazine versus TIPS-pentacene: Enhanced electron mobility for n-type organic field-effect transistors, Org. Electron. 13 (2012) 1392-1400. doi:10.1016/j.orgel.2012.04.010.

[25] G. Gruntz, H. Lee, L. Hirsch, F. Castet, T. Toupance, A.L. Briseno, et al., Nitrile substitution effect on triphenodioxazine-based materials for liquid-processed airstable n-type organic field effect transistors, Adv. Electron. Mater. 1 (2015) 1500072. doi:10.1002/aelm.201500072.

[26] S. Jung, M. Albariqi, G. Gruntz, T. Al-Hathal, A. Peinado, E. Garcia-Caurel, et al., A TIPS-TPDO-tetraCN-based n-type organic field-effect transistor with a crosslinked PMMA polymer gate dielectric, ACS Appl. Mater. Interfaces. 8 (2016) 14701-14708. doi:10.1021/acsami.6b00480.

[27] I.S. Kirin, P.N. Moskalev, Y.A. Makashev, Formation of unusual phthalocyanines of the rare-earth elements, Russ. J. Inorg. Chem. 10 (1965) 1065-1066.

[28] C. Clarisse, M.T. Riou, Synthesis and characterization of some lanthanide phthalocyanines, Inorg. Chim. Acta. 130 (1987) 139-144. doi:10.1016/S00201693(00)85943-5.

[29] P. Gaudillat, A. Wannebroucq, J.-M. Suisse, M. Bouvet, Bias and humidity effects on the ammonia sensing of perylene derivative/lutetium bisphthalocyanine MSDI heterojunctions, Sens. Actuators: B. Chem. 222 (2016) 910-917. doi:10.1016/j.snb.2015.09.015.

[30] R. Even, J. Simon, D. Markovitsi, Optical properties of thin films of molecular semiconductors, Chem. Phys. Lett. 156 (1989) 609-614. doi:10.1016/S00092614(89)87241-0.

[31] E. Orti, J.L. Brédas, C. Clarisse, Electronic structure of phthalocyanines: Theoretical investigation of the optical properties of phthalocyanine monomers, dimers, and crystals, J. Chem. Phys. 92 (1990) 1228-1235. doi:10.1063/1.458131.

[32] C. Lemmer, M. Bouvet, R. Meunier-Prest, Proton coupled electron transfer of ubiquinone Q2 incorporated in a self-assembled monolayer, Phys. Chem. Chem. Phys. 13 (2011) 13327-13332. doi:10.1039/c0cp02700f.

[33] A. Bolognese, C. Piscitelli, G. Scherillo, Formation of dihydrotriphenodioxazines and dihydroisotriphenodioxazines by acidic treatment of some substituted $3 \mathrm{H}$ - 
phenoxazin-3-ones; isolation and characterization. A new perspective in the chemistry of ommochromes, J. Org. Chem. 48 (1983) 3649-3652. doi:10.1021/jo00169a006.

[34] R. Meunier-Prest, G. Gruntz, A. Wannebroucq, M. Bouvet, T. Toupance, Y. Nicolas, to be submitted.

[35] Y. Chen, D. Li, N. Yuan, J. Gao, R. Gu, G. Lu, et al., Tuning the semiconducting nature of bis(phthalocyaninato) holmium complexes via peripheral substituents, J. Mater. Chem. 22 (2012) 22142-22149. doi:10.1039/c2jm35219b.

[36] X. Kong, Z. Dong, Y. Wu, X. Li, Y. Chen, J. Jiang, High sensitive ambipolar response towards oxidizing $\mathrm{NO}_{2}$ and reducing $\mathrm{NH}_{3}$ based on bis(phthalocyaninato) europium semiconductors, Chin. J. Chem. 34 (2016) 975-982. doi:10.1002/cjoc.201600490.

[37] B. Timmer, W. Olthuis, A.V.D. Berg, Ammonia sensors and their applications-a review, Sens. Actuators: doi:10.1016/j.snb.2004.11.054.

B. Chem. 107 (2005) 666-677. 